\title{
Michel M. Ter-Pogossian (1925-1996): a pioneer of positron emission tomography weighted in fast imaging and 0xygen-15 application
}

\author{
Iwao Kanno ${ }^{1} \cdot$ Miwako Takahashi $^{1} \cdot$ Taiga Yamaya $^{1}$ \\ Published online: 11 December 2019 \\ ๑) Japanese Society of Radiological Technology and Japan Society of Medical Physics 2019
}

\section{Introduction}

Michel M. Ter-Pogossian (Fig. 1) was a great pioneer in the field of nuclear medicine. His achievements include the development and medical use of the cyclotron, realization of a positron emission tomography (PET) scanner, timeof-flight (TOF) implementation in PET, and clinical use of Oxygen-15 $\left({ }^{15} \mathrm{O}\right)$ tracers.

He was born on April 21, 1925. He received his undergraduate and graduate degrees from the Paris University, France, and received his master's and doctoral degrees from the Washington University, St. Louis. He joined the faculty of the Washington University School of Medicine in 1950 as an instructor, and from 1961, he held a professorship in Radiation Physics and Physiology. He was also director of Mallinckrodt Institute's Division of Radiation Sciences from 1963 to 1991 . He was the first editor of the IEEE Transactions on Medical Imaging. Unfortunately, on June 19, 1996, he suddenly died in Paris due to a heart attack; he was 71 years old. We believe that, if Ter-Pogossian had lived another 10 years, he would have won the Nobel Prize for his contributions to innovation in PET.

He received many awards for his pioneering work related to the medical use of the cyclotron, ${ }^{15} \mathrm{O}$ tracer study, its kinetic analysis, and PET system development. These many honors were an expression of his ability to collaborate with many other experts from different disciplines, both as a leader and as a team player. His scientific accomplishments were based on his endless motivation for understanding biology and medicine. He published a textbook on diagnostic radiology as a summary of his early carrier in 1967, which

Iwao Kanno

kanno1009@gmail.com

1 National Institute of Radiological Sciences, National Institutes for Quantum and Radiological Science and Technology, 4-9-1 Anagawa, Inage-ku, Chiba 263-8555, Japan has been recognized as the first textbook in the field of diagnostic radiology physics [1]. From him, we can learn that achievements in nuclear medicine require inputs of many specialists, such as physicians, physicists, engineers, physiologists, chemists, computer scientists, and other philosophies of nature.

\section{The short-lived radionuclide and cyclotron}

Initially, ${ }^{15} \mathrm{O}$ was thought to be clinically useless because of its very short half-life (122.5 s), but Ter-Pogossian used it once again for physiological studies [2, 3]. He had learned about the behavior of ${ }^{15} \mathrm{O}$ gas from West and Dollery at the Hammersmith Hospital in 1950 [4]. He recognized that "metabolic oxidation was a process which in most of its stages was comparable in time scale to the ${ }^{15} \mathrm{O}$ half-life." [5]. Oxygen $\left(\mathrm{O}_{2}\right)$ has various features with different biochemical behaviors; $\mathrm{O}_{2}$ combines with hemoglobin and is metabolized into $\mathrm{H}_{2} \mathrm{O}$ which is perfused into the blood stream, $\mathrm{CO}$ strongly combines with hemoglobin which circulates as a red blood cell, and inhaled $\mathrm{CO}_{2}$ is immediately converted into $\mathrm{H}_{2} \mathrm{O}$ by carbon anhydride in the lungs [6]. Therefore, ${ }^{15} \mathrm{O}$ was used as ${ }^{15} \mathrm{O}-\mathrm{O}_{2},{ }^{15} \mathrm{O}-\mathrm{CO}$ and ${ }^{15} \mathrm{O}-\mathrm{CO}_{2}$, for respiratory and cerebral metabolic studies. His vision of the physiological aspects of these short-lived radionuclides enabled the installation of cyclotrons in many medical facilities [7], which also generated a strong demand for more compact and less expensive cyclotrons.

To investigate a compact cyclotron for flexible supply of various radionuclides at the Mallinckrodt Institute, TerPogossian visited Japan in the mid-1980s to inspect a compact cyclotron produced by Japan Steel Works (JSW) Ltd. Then, he visited several Japanese PET centers where the JSW cyclotron was already running. One of these places was the Akita-PET center, Research Institute of Brain and Blood Vessels, where he saw a JSW compact cyclotron running in stable and flexible condition. Kanno, the 


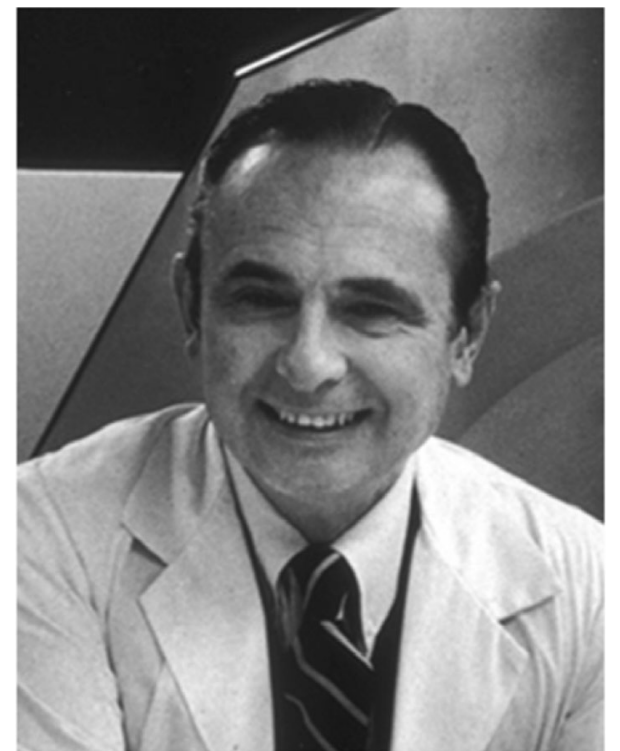

Fig. 1 Michel M. Ter-Pogossian (Reproduced with permission from Becker Medical Library, Washington University School of Medicine)

co-author of this article, remembers that Ter-Pogossian was very satisfied with the JSW cyclotron for the extensive use of ${ }^{15} \mathrm{O}$-PET for stroke patients.

\section{The motivation for brain biology}

Ter-Pogossian enthusiastically promoted the use of ${ }^{15} \mathrm{O}$ for evaluating brain and heart functions and their diseases. In a study, a small volume of blood with radioactive ${ }^{15} \mathrm{O}$ labeled hemoglobin $\left({ }^{15} \mathrm{O}-\mathrm{Hb}\right)$ was rapidly injected into the internal carotid artery of a patient. The second injection was done under identical circumstances but with blood labeled with ${ }^{15} \mathrm{O}-\mathrm{H}_{2} \mathrm{O}$. After each injection, the distribution of radioactivity was measured and recorded as a function of time. Six collimated scintillation probes were placed over the subject's head (Fig. 2). Through his analysis, the data provided a measurement of fractional oxygen utilization in the brain and regional cerebral oxygen utilization rates [6].

The theory of ${ }^{15} \mathrm{O}$-gas steady-state inhalation method to measure the regional cerebral blood flow (rCBF) and the regional cerebral metabolic rate of oxygen $\left(\mathrm{rCMRO}_{2}\right)$, which is now widely used in PET protocol, was developed by T. Jones at the Hammersmith Hospital in London after his visit to the Washington University $[8,9]$. In the mid1980s, a group at the Washington University developed an alternative method that cut the measurement time in half, opening up a new horizon in brain sciences $[10,11]$.

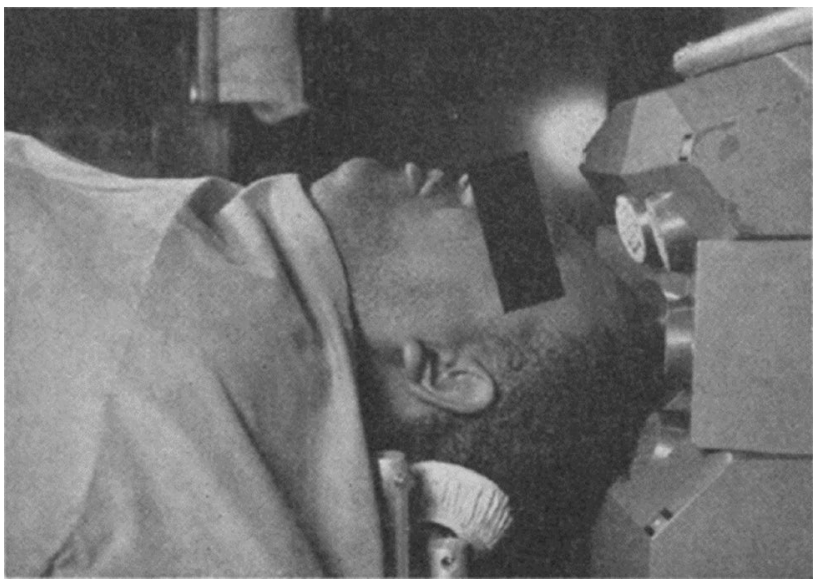

Fig. 2 The scintillation probes used to measure ${ }^{15} \mathrm{O}$ radioactivity concentration in the head. Two sets of three probes were symmetrically positioned [6] (Reproduced with permission from American Society for Clinical Investigation)

\section{The development of PET}

Ter-Pogossian played an important role as a pioneer of PET equipment development. His efforts to develop tomographic devices capable of imaging the distribution of short-lived radioisotopes began in the 1950s. In early studies using positron-emitting nuclides, annihilation radiation was detected by detectors equipped with collimators (lead or tungsten) that restricted the direction of incoming photons. In the early 1960s, Rankowitz et al. developed a positron scanner which consisted of scintillation detectors designed for coincidence detection, which simultaneously detects two $511 \mathrm{keV}$ photons emitted at $180^{\circ}$ through the annihilation reaction of electrons and positrons. In the early 1970s, Ter-Pogossian's team developed a hexagonal system aiming for clinical human studies, which they named as positron emission transverse tomograph (PETT) [12]. After the first PETT development, Phelps, who was a younger co-worker of Ter-Pogossian, left the laboratory. Phelps and his colleagues intended to develop a PET system with a higher spatial resolution, for which they used new scintillation crystals with a high-Z, i.e. bismuth germanium oxide (BGO) [13]. In contrast, Ter-Pogossian decided to improve the timing performance of PET systems aiming towards the imaging of short-lived radioisotopes (Fig. 3).

The PETT-III, which was a clinical version of the PETT, was used extensively in animal and patient studies at the Washington University and later at the Brookhaven National Laboratory. The encouraging results obtained from PET studies using short-lived physiological radionuclides stimulated tomographic reconstructions. 


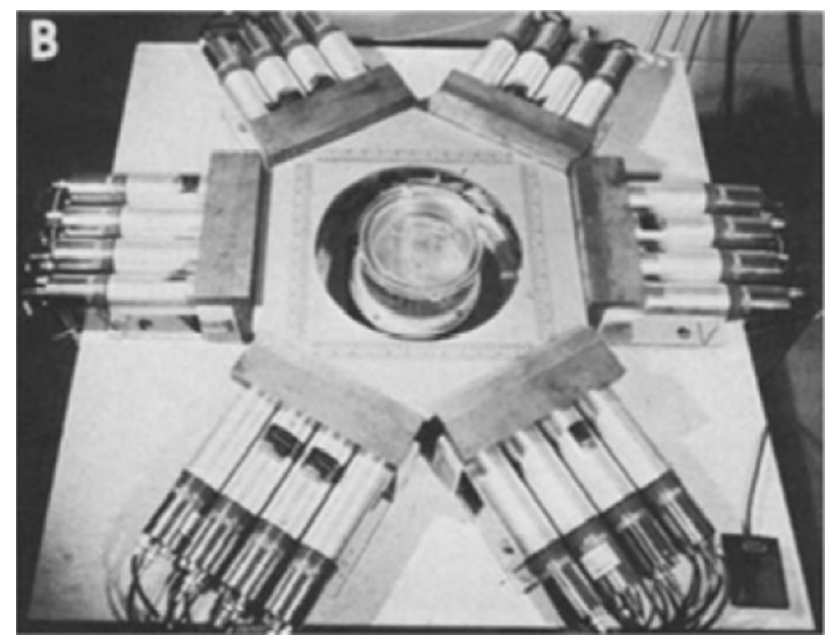

Fig. 3 A photograph of Ter-Pogossian's PETT prototype with a phantom placed on a turntable at the center of the hexagon [12] (Reproduced with permission from the Radiological Society of North America)

Additionally, it also stimulated other different fields of study, such as chemists who had renewed ambitions in labeling complex molecules with short-lived positronemitting radionuclides [14]. Shortly after, Ter-Pogossian developed the next PET version, the PETT-IV (Fig. 4) which he designed and built to yield tomographic images using a multi-slice detector arrangement. This multi-slice device was based on the premises that the structures to be imaged in nuclear medicine are three-dimensional, that the time interval that occurred from repetitive use of a single slice was not negligible because the physiological tracer moves dynamically in the in vivo study, and that the multi-slice detector had an improved system sensitivity [15]. Thereafter, he developed the PETT-V, which was a brain-dedicated scanner. He changed the arrangement of the detector from the hexagonal array to a circular array [16] (Fig. 5). The next PETT version (PETT-VI) used a new scintillator, cesium fluoride $(\mathrm{CsF})$, which had the shortest fluorescence decay time among the affordable scintillation crystals at that time. Moreover, the PETT-VI had 4 rings with 72 scintillation detectors [17]. Finally, the short resolving time permitted rapid data acquisition of dynamic kinetics of the tracers labeled with ${ }^{15} \mathrm{O}$.

\section{Challenge to TOF-PET}

The principle of the PET coincidence detector relies on (1) annihilation photons emitted in the opposite direction and (2) the photons are emitted simultaneously. Therefore, the time differences between the opposite detectors detecting photons can be converted to the localization of the annihilation event along the line between the opposite detectors. However, the speed of light is very fast and there are limitations concerning the time resolution of each of the components of PET systems. Although practical detector timing resolution was far from localization of positron annihilation location, Ter-Pogossian thought that the TOF information should be useful to narrow the possible area, which would increase the signal-to-noise ratio of PET images. He checked and investigated each hardware component and software necessary for the TOF-PET. With state-of-the-art materials and electronic components such as $\mathrm{CsF}$, photomultiplier tube
Fig. 4 Diagram of the PETT IV showing the detectors, collimators, and the septa arrangement [15] (Reproduced with permission from the Radiological Society of North America)
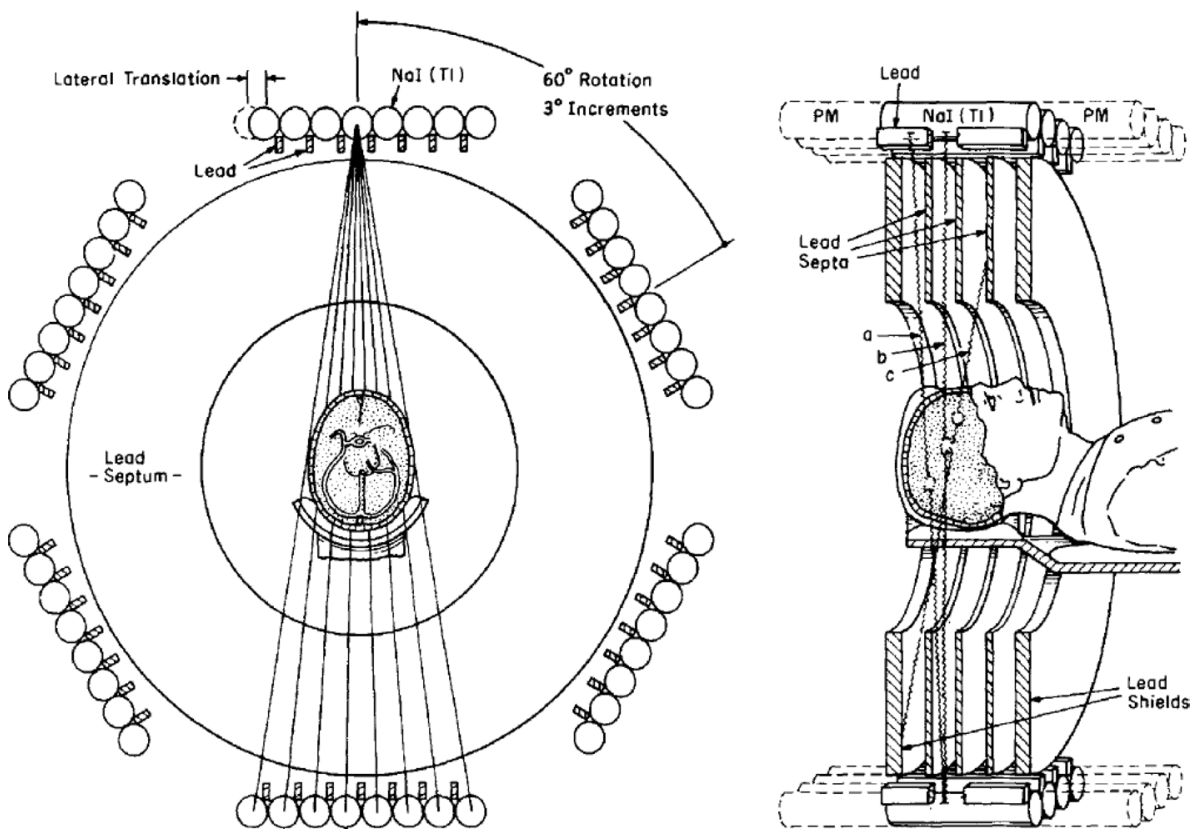


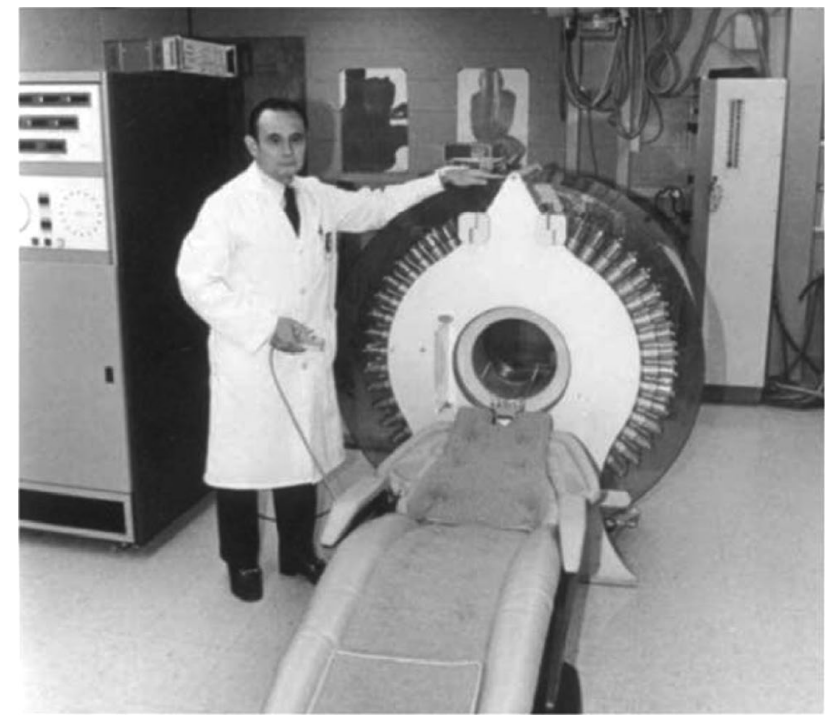

Fig. 5 Photograph of Michel M. Ter-Pogossian next to the PETT-V (Reproduced with permission from Becker Medical Library, Washington University School of Medicine)

(mainly Hamamatsu produced the best performance), and mathematical consideration, he successfully incorporated TOF information into the image reconstruction algorithm, achieving a dramatic improvement in the signal-to-noise ratio of the PET images [18-20].

\section{In our memories}

In the late 1970s, when Ter-Pogossian came to Kyoto, Kanno asked him a direct question; what is the best method to measure cerebral blood flow (CBF)? He then immediately replied, "It's the microsphere method because of the least hypothesis for measuring quantitative CBF." Initially, Kanno could not understand his answer, because the microsphere method was not applicable in human studies. Kanno expected a different response because they had just developed an innovative method for measuring CBF using inert radioactive gas and its tomographic concentration [21]. To this day, Kanno remembers fondly Ter-Pogossian's sincere response to a stupid young man.

In the early 1980s, he was invited to an international PET meeting in Sendai, Japan. Kanno asked about the future of PET. He then immediately replied that PET would be a leading device and would replace all other imaging methods in nuclear medicine. However, at the time of writing this article, non-PET nuclear medicine imaging methods such as SPECT still have strong demands for clinical uses. His prediction was not completely true, but easier-to-install accelerators with less expensive costs are now commercially supplied by several companies. The next-generation PET technologies have been developed worldwide, providing us with a great deal of knowledge about physiology and pathophysiology. Furthermore, many patients suffering from different diseases are relying on PET and waiting for further innovations in nuclear medicine.

\section{References}

1. Ter-Pogossian MM. Physical aspect of diagnostic radiology. 1967. (Hoeber)

2. Ter-Pogossian MM, Powers W.E. The use of radioactive Oxygen-15 in the determination of oxygen content in malignant neoplasm. Radioisotopes in scientific research. In: Proceedings of the 1st UNESCO international conference, vol 3. Paris 1957. New York: Pergamon; 1958.

3. Ter-Pogossian MM. Cyclotron produced short-lived radioactive isotopes. Am J Roentgenol Radium Ther Nucl Med. 1966;96:737-43.

4. Dollery CT, West JB. Regional uptake of radioactive oxygen, carbon monoxide and carbon dioxide in the lungs of patients with mitral stenosis. Circ Res. 1960;8:765-71.

5. Ter-Pogossian MM, Herscovitch P. radioactive Oxygen-15 in the study of cerebral blood flow, blood volume, and oxygen metabolism. Semin Nucl Med. 1985;15:377-94.

6. Ter-Pogossian MM, Eichling JO, Davis DO, Welch MJ. The measure in vivo of regional cerebral oxygen utilization by means of oxyhemoglobin labeled with radioactive Oxygen-15. J Clin Invest. 1970;49:381-91.

7. Ter-Pogossian MM, Wagner HN Jr. A new look at the cyclotron for making short-lived isotopes. Semin Nucl Med. 1998;28:202-12.

8. Jones T, Chesler DA, Ter-Pogossian MM. The continuous inhalation of Oxygen-15 for assessing regional oxygen extraction in the brain of man. Br J Radiol. 1976;49:339-43.

9. Frackowiak RS, Lenzi GL, Jones T, Heather JD. Quantitative measurement of regional cerebral blood flow and oxygen metabolism in man using 150 and positron emission tomography: theory, procedure, and normal values. J Comput Assist Tomogr. 1980;4:727-36.

10. Herscovitch P, Markham J, Raichle ME. Brain blood flow measured with intravenous H2(15)O. I. Theory and error analysis. J Nucl Med. 1983;24:782-9.

11. Mintun MA, Raichle ME, Martin WR, Herscovitch P. Brain Oxygen utilization measured with O-15 radiotracers and positron emission tomography. J Nucl Med. 1984;25:177-87.

12. Ter-Pogossian MM, Phelps ME, Hoffman EJ, Mullani NA. A positron-emission transaxial tomograph for nuclear imaging (Pett). Radiology. 1975;114:89-988.

13. Cho ZH, Farukhi MR. Bismuth germanate as a potential scintillation detector in positron cameras. J Nucl Med. 1977;18:840-4.

14. Fowler JS, Wolf AP. New developments in radiotracers for positron emission tomography. NIDA Res Monogr. 1991;112:146-67.

15. Ter-Pogossian MM, Mullani NA, Hood J, Higgins CS, Currie CM. A multislice positron emission computed tomograph (pett iv) yielding transverse and longitudinal images. Radiology. 1978;128:477-84.

16. Ter-Pogossian MM, Mullani NA, Hood JT, Higgins CS, Ficke DC. Design considerations for a positron emission transverse tomograph (Pett V) for imaging of the brain. J Comput Assist Tomogr. 1978;2:539-44.

17. Ter-Pogossian MM, Ficke DC, Hood JT Sr, Yamamoto M, Mullani NA. Pett Vi: a positron emission tomograph utilizing cesium fluoride scintillation detectors. J Comput Assist Tomogr. 1982;6:125-33. 
18. Ter-Pogossian MM, Ficke DC, Yamamoto M, Hood JT. Super Pett I: a positron emission tomograph utilizing photon time-of-flight information. IEEE Trans Med Imaging. 1982;1:179-87.

19. Ter-Pogossian MM, Mullani NA, Ficke DC, Markham J, Snyder DL. Photon time-of-flight-assisted positron emission tomography. J Comput Assist Tomogr. 1981;5:227-39.

20. Ter-Pogossian MM, Ficke DC, Beecher DE, Hoffman GR, Bergmann SR. The Super Pet 3000-E: a pet scanner designed for high count rate cardiac applications. J Comput Assist Tomogr. 1994;18:661-9.
21. Kanno I, Lassen NA. Two methods for calculating regional cerebral blood flow from emission computed tomography of inert gas concentrations. J Comput Assist Tomogr. 1979;3:71-6.

Publisher's Note Springer Nature remains neutral with regard to jurisdictional claims in published maps and institutional affiliations. 